\title{
Inibição da expressão de ciclooxigenase 2 em feridas cutâneas de camundongos NOD submetidos à terapia a laser de baixa intensidade
}

\author{
Inhibition of cyclooxygenase 2 expression in NOD mice cutaneous wound by low-level laser therapy \\ Carolina de Lourdes Julião Vieira Rocha', Adeir Moreira Rocha Júnior², Beatriz Julião Vieira Aarestrup, Fernando Monteiro Aarestrup ${ }^{4}$
}

\section{Resumo}

Contexto: A terapia a laser de baixa intensidade (LLLT) tem sido relatada como importante moduladora da cicatrização de feridas cutâneas aumentando a proliferação fibroblástica associada ao aumento da expressão da citocina fator transformador de crescimento- $\beta 2$ (TGF- $\beta$ B2).

Objetivo: No presente estudo foram avaliados os efeitos da LLLT sobre a expressão da enzima ciclooxigenase 2 (COX2) no sítio do reparo tecidual utilizando o modelo experimental com camundongos diabéticos não obesos (NOD) para estudar a cicatrização de feridas cutâneas.

Métodos: Foram utilizados 30 camundongos NOD, destes 14 ficaram diabéticos e foram divididos em dois grupos: o grupo I ( $n=7$ ) foi submetido a um procedimento cirúrgico de feridas cutâneas e o grupo II $(n=7)$ foi submetido a um procedimento cirúrgico de feridas cutâneas e tratados com LLLT. O grupo II foi submetido à LLLT nos seguintes parâmetros: $15 \mathrm{~mW}$ de potência, dose de 3,8//cm² e tempo de aplicação de 20 segundos. Após sete dias do ato cirúrgico e após aplicação do laser, os animais foram eutanasiados com sobredose de anestesia e amostras das feridas foram colhidas para posterior análise histopatológica, histomorfométrica e imuno-histoquímica.

Resultados: A LLLT promoveu a inibição da expressão da COX2 em feridas cutâneas de camundongos diabéticos.

Conclusão: Em conjunto, os resultados sugeriram que a LLLT é capaz de modular negativamente a expressão da enzima COX2 contribuindo para o controle da resposta inflamatória em feridas cutâneas de camundongos NOD.

Palavras-chave: camundongos endogâmicos NOD; ciclooxigenase 2; terapia a laser de baixa intensidade.

\begin{abstract}
Background: Low-level laser therapy (LLLT) has been reported to modulate the healing of wounds by inducing an increase in fibroblast number associated with increased expression of the cytokine transforming growth factor- $\beta_{2}$ (TGF- $\beta_{2}$ ).

Objective: In the present study, the effect of LLLT on expression of COX2 at the site of tissue repair was evaluated, using an experimental model with non obese diabetic mice (NOD) to study cutaneous wound healing.

Methods: Thirty NOD mice were used, of which 14 were diabetic and were divided into two groups: group I ( $n=7$ ) underwent a surgical procedure of skin wounds and group II $(n=7)$ underwent a surgical procedure of skin wounds and treated with LLLT. Group II was submitted to LLLT in the following parameters: $15 \mathrm{~mW}$ of power, dose of $3.8 \mathrm{~J} / \mathrm{cm}^{2}$ and exposure time of 20 seconds. Seven days after surgery and after laser application, animals were euthanized with an overdose of anesthesia and tissue samples were collected for subsequent histological analysis, histomorphometry and immunohistochemistry.

Results: The LLLT has promoted the inhibition of COX2 expression in skin wounds in mice diabetic.

Taken together the results suggest that LLLT modulate the expression of COX2 improved the control of inflammatory reaction in cutaneous wound lesions in NOD mice.

Conclusion: Taken together, the results suggested that LLLT is able to negatively modulate the expression of COX2 enzyme contributing to the inflammatory response in cutaneous wounds in NOD mice.
\end{abstract}

Keywords: mice, inbred NOD; cyclooxygenase 2; laser therapy, low-level.

Trabalho realizado no Laboratório de Imunopatologia e Patologia Experimental do Centro de Biologia da Reprodução da Universidade Federal de Juiz de Fora (UFJF) - Juiz de Fora (MG), Brasil. ${ }^{1}$ Aluna de Pós-graduação em Saúde Brasileira pela Faculdade de Medicina da Universidade Federal de Juiz de Fora (UFJF) - Juiz de Fora (MG), Brasil.

${ }^{2}$ Professor Assistente da Faculdade de Ciências Médicas e da Saúde de Juiz de Fora (SUPREMA) - Juiz de Fora (MG), Brasil.

${ }^{3}$ Professora Adjunta do Departamento de Morfologia do Instituto de Ciências Biológicas, Setor Histologia da UFJF; Pesquisadora Associada do Laboratório de Imunopatologia e Patologia Experimental do Centro de Biologia da Reprodução da UFJF - Juiz de Fora (MG), Brasil.

${ }^{4}$ Professor Associado III; Chefe do Laboratório de Imunopatologia e Patologia Experimental do Centro de Biologia da Reprodução da UFJF - UFJF - Juiz de Fora (MG); Professor Titular da Faculdade de Medicina da Fundação Dom André Arcoverde (FAA) - Juiz de Fora (MG), Brasil.

Fonte de financiamento: Fundação de Amparo à Pesquisa do Estado de Minas Gerais (FAPEMIG): Rede Mineira de Bioterismo (Processo n 172/08) e Rede Mineira de Ensaios Toxicológicos e Farmacológicos de Produtos Terapêuticos (Processo nº 173/08).

Conflito de interesse: nada a declarar.

Submetido em: 16.12.09. Aceito em: 29.02.12

J Vasc Bras. 2012;11(3):175-181. 


\section{Introdução}

O diabetes mellitus (DM) é uma síndrome de etiologia múltipla, decorrente da falta de insulina e/ou da incapacidade da insulina exercer adequadamente seus efeitos. A doença é um problema mundial de saúde pública, de incidência elevada, em termos de pessoas afetadas, incapacitações e mortalidade prematura ${ }^{1}$. Estudos epidemiológicos indicam um aumento considerável da prevalência, tanto do DM tipo I (DM1) quanto o DM tipo 2 (DM2) ${ }^{2}$. As complicações crônicas inerentes ao DM merecem destaque pela alta morbidade e caráter incapacitante como as úlceras de membros inferiores. Tal processo é denominado pé diabético que pode acarretar amputação do membro afetado ${ }^{1,3-5}$.

Estudos realizados em modelos animais, in vitro e em humanos a respeito desta doença estão sendo cada vez mais difundidos a fim de prevenir, retardar e tratar as possíveis complicações. Novas possibilidades terapêuticas estão sendo preconizadas utilizando a terapia laser de baixa intensidade (LLLT) no processo de reparo tecidual. Esta terapia demonstra ser um recurso eficaz na diminuição do tempo de reposição tecidual, ou seja, melhora a qualidade da reparação tecidual e acelera o processo de cicatrização ${ }^{6-9}$.

Modelos experimentais de diabetes em murinos estão sendo amplamente estudados a fim de esclarecer o mecanismo fisiopatológico da doença. O camundongo diabético não obeso (NOD) é amplamente utilizado em trabalhos experimentais por apresentar um genoma bem definido que induz o desenvolvimento espontâneo de um quadro fenotípico de DM1 ${ }^{10-13}$

Diversos pesquisadores têm estudado o papel imunomodulador pró-inflamatório da interação de mediadores inflamatórios, como por exemplo, os efeitos do óxido nítrico (NO) através da elevação dos níveis de ciclooxigenase 2 (COX2) no sítio inflamatório induzindo a vasodilatação e a migração de células para o local da lesão tecidual ${ }^{14-17}$. No presente estudo, avaliou-se o efeito da LLLT sobre a síntese de COX2 durante a resposta cicatricial em feridas cutâneas em camundongos diabéticos.

\section{Método}

\section{Animais}

Foram utilizados 30 camundongos NOD, fêmeas, com 120 a 150 dias de idade e, em média, 20 gramas de peso. Dos 30 camundongos NOD selecionados para a pesquisa, 14 ficaram diabéticos (46,6\%). Tal porcentagem é compatível com a observada na literatura ${ }^{11-13}$. Os animais foram obtidos no
Biotério da Fundação Osvaldo Cruz, Salvador (BA). Os animais foram alojados no Biotério do Núcleo Biomédico da Faculdade de Medicina da Fundação Dom André Arcoverde, Valença (RJ) e mantidos segundo critérios preestabelecidos pelo Colégio Brasileiro de Experimentação Animal.

Os camundongos selecionados para o experimento $(\mathrm{n}=14)$ foram divididos de forma aleatória em dois grupos com sete animais cada: grupo I, controle, composto por camundongos NOD não submetidos à LLLT e grupo II, tratado, composto por camundongos NOD submetidos à LLLT.

\section{Modelo experimental}

Os animais foram submetidos a dosagens glicêmicas diárias. A avaliação da glicemia nos animais foi realizada através da coleta de uma gota de sangue da veia dorsal da cauda e a aferição foi feita utilizando-se fitas reagentes de medição de glicemia acopladas ao medidor Accu-Check Advantage ${ }^{\circledR}$. Foram considerados diabéticos os camundongos NOD que apresentaram glicemia maior ou igual a $250 \mathrm{mg} / \mathrm{dL}$.

Os animais foram previamente anestesiados com $100 \mathrm{mg} / \mathrm{kg}$ de quetamina e $10 \mathrm{mg} / \mathrm{kg}$ de xilasina, em seguida, foram submetidos a um procedimento cirúrgico para a remoção de um fragmento circular de tecido cutâneo de aproximadamente $10 \mathrm{~mm}$ de diâmetro na região dorsal com auxílio de um bisturi. $\mathrm{O}$ aparelho utilizado no grupo tratado foi o Twin Laser de emissão infravermelha, pulsátil, com semicondutores de arsênio e gálio, comprimento de onda de $780 \mathrm{~nm}$, potência de pico de $70 \mathrm{~mW}$, potência média de saída de 0,5 a 3,5 mW e aplicação através de fibra ótica. No grupo controle não foi realizado nenhum tratamento; no grupo II, as feridas experimentais foram submetidas à LLLT nos seguintes parâmetros: $15 \mathrm{~mW}$ de potência, dose de $3,8 \mathrm{~J} / \mathrm{cm}^{2}$ e 20 segundos de aplicação. A primeira aplicação foi realizada logo após o ato cirúrgico e uma segunda aplicação 48 horas após o procedimento cirúrgico. Foi realizada aplicação do laser pelo método pontual em um tempo de 20 segundos, englobando a área central e as bordas adjacentes à lesão a fim de tratar a área uniformemente. Decorridos sete dias do ato cirúrgico e após aplicação do laser, todos os animais foram eutanaziados através de sobredose de anestesia. Posteriormente, foram coletadas amostras das lesões contendo, na sua profundidade, parte da pele adjacente às bordas da ferida e todo o tecido cicatricial.

\section{Histopatologia e histomorfometria}

Todas as amostras das lesões cutâneas foram submetidas a análises histopatológica e histomorfométrica. As 
amostras de pele foram fixadas em formol tamponado $10 \%$ ( $\mathrm{pH}$ 7) por período mínimo de 24 horas. Após a fixação, houve desidratação gradativa em concentrações crescentes de álcool etílico (70 a 100\%), diafanizadas em xilol, embebidas e incluídas em parafina, conforme métodos histológicos de rotina. Posteriormente, as amostras foram submetidas à microtomia utilizando-se micrótomo modelo 820 Spence, com seções de $5 \mu \mathrm{m}$ de espessura. Foram realizados cortes histológicos em duas diferentes profundidades de cada amostra coletada. As lâminas histológicas foram mantidas em estufa para secagem e os cortes submetidos à coloração por hematoxilina e eosina para posterior análise.

Foi realizada a captura de imagens com câmera digital e posteriormente avaliadas por sistema computadorizado de captura de imagens Axiostar Plus (Zeiss, Berlin, Alemanha). As imagens de todos os campos microscópicos de cada amostra foram capturadas com aumento original de 400X e a contagem de células inflamatórias e vasos por campo microscópico foi realizada com auxílio de marcação digital.

\section{Imuno-histoquímica}

O estudo imuno-histoquímico foi realizado através do emprego do método do complexo avidina-biotina peroxidase anti-peroxidase $(\mathrm{ABC})$ para verificar a expressão de COX2, afim de elucidar o mecanismo de ação da LLLT em lesões cutâneas de camundongos diabéticos.

O método foi realizado nas seguintes etapas: a) Fixação em acetona (10 min); b) Reidratação dos cortes em PBS, pH 7,4 (10 min); c) Bloqueio da peroxidase endógena com solução de peróxido de hidrogênio 0,4\% (30 min); d) Lavagem em PBS (10 min); e) Incubação com soro normal de cavalo (Vector Laboratory, Inc., Burlington, Califórnia, EUA) em câmara úmida (20 min); f) Incubação com o anticorpo primário policlonal anti-COX2, rabbit polyclonal IgG (Santa Cruz Biotechnology, Califórnia, EUA), diluição 1:100 (1 h); g) Lavagem em PBS (10 min); h) Incubação com anticorpo secundário de cabra biotinilado anti-IgG de coelho (Dakopatts, Copenhagen, Dinamarca) diluição 1:100 em PBS (30 min); i) Lavagem em PBS (30 min); j) Incubação com tampão acetato 0,2 M, pH 5,2 (10 min); l) Revelação do produto da reação imunológica empregando a solução de 3-amino-9-eticarbazol (1 a $3 \mathrm{~min}$ ); m) Lavagem em água corrente (10 min); n) Contracoloração com hematoxilina de Harris (1 min); o) Lavagem em água corrente (10 min); p) Montagem da lâmina com Elvanol (polivinilálcool) e lamínula.

O controle da reação imuno-histoquímica foi realizado omitindo-se, em alguns cortes, a etapa de incubação com o anticorpo primário. Imagens dos campos analisados foram obtidas através do sistema computadorizado de análise de imagens, AxioVision (Axiostar Zeiss, Carl Zeiss, Hamburg, Alemanha). Foi realizada captura de imagens de quatro campos aleatórios de cada lâmina histológica com câmera digital (aumento total 400X) do microscópio modelo Axiostar Plus (Zeiss, Berlin, Alemanha). Ao final do experimento com auxílio de marcação digital, as imagens foram arquivadas e submetidas à contagem de células inflamatórias e número de vasos sanguíneos.

\section{Análise estatística}

A análise estatística dos resultados foi obtida utilizando-se os métodos não-paramétricos Mann-Whitney e o teste $t$ de Student com nível de significância $\mathrm{p}<0,05$.

\section{Resultados}

No sétimo dia pós-operatório, a observação clínica das amostras das lesões cutâneas dos animais de ambos os grupos do experimento apresentava uma pequena quantidade de coágulo sobre a superfície da ferida, com presença de vasos sanguíneos na profundidade da hipoderme.

As lesões cutâneas do grupo controle apresentaram padrão de reparação tecidual em fase inicial, com formação de crosta e bordas elevadas com centro avermelhado devido à presença de tecido de granulação na área lesionada. Entretanto, as lesões cutâneas dos animais tratados com LLLT apresentaram aspecto de adiantada reparação tecidual, inclusive com presença de pelos.

A análise histopatológica revelou, nas amostras dos animais do grupo controle, uma discreta proliferação epitelial, porém com ampla área de material fibro-necrótico sobre a lesão. Nestas amostras cutâneas foi evidenciado um infiltrado inflamatório mononuclear bem desenvolvido, representado principalmente por linfócitos e macrófagos. Nos animais do grupo tratado, foi constatada uma diminuição da intensidade do infiltrado inflamatório (Figuras 1A e 1B). A análise histomorfométrica revelou que embora a LLLT promova a diminuição do desenvolvimento do infiltrado inflamatório, estatisticamente o resultado não foi significante $(p<0,05)$. Os resultados acima mencionados são apresentados no Gráfico 1.

A avaliação do número de vasos sanguíneos por campo microscópico (Gráfico 2) revelou que as feridas cutâneas dos animais tratados com a LLLT apresentavam uma quantidade maior de vasos sanguíneos quando comparadas com as amostras do grupo controle. Entretanto, similar ao que 
foi observado na análise da intensidade do infiltrado inflamatório, os resultados não foram estatisticamente significativos $(\mathrm{p}<0,05)$.

A presença de células inflamatórias produtoras de COX2 foi avaliada utilizando-se o método imuno-histoquímico. Os animais que foram submetidos à LLLT apresentavam uma porcentagem significativamente maior de células inflamatórias expressando a enzima COX2 (Gráfico 3), evidenciada pela marcação intracitoplasmática (Figuras $2 \mathrm{~A}$ e 2B), quando comparados aos animais do grupo controle.

\section{Discussão}

Em 2007, a população brasileira entre 20 e 79 anos de idade contava com 119 milhões e 519 mil indivíduos, entre os quais a International Diabetes Federation (IDF) constatou que 6 milhões e 913 mil (5,8\%) eram portadores de diabetes. Diante disto, a IDF realizou um cálculo de prevalência desta mesma população para o ano de 2025 e constatou um crescente aumento percentual de 11,4\% (17 milhões e 627 mil pacientes) ${ }^{3}$. Além da taxa de incidência, destaca-se o fato de que algumas complicações inerentes ao diabetes levam o paciente a morbidade e mortalidade prematuras. As complicações crônicas mais comuns apresentadas por estes indivíduos são as doenças cardiovasculares (infarto agudo do miocárdio), os acidentes vasculares cerebrais, as nefropatias, as neuropatias, as retinopatias diabéticas e o pé diabético ${ }^{1}$. Os pacientes portadores de diabetes possuem deficiência cicatricial apresentando evolução mais lenta na reparação de lesões quando comparados a pessoas

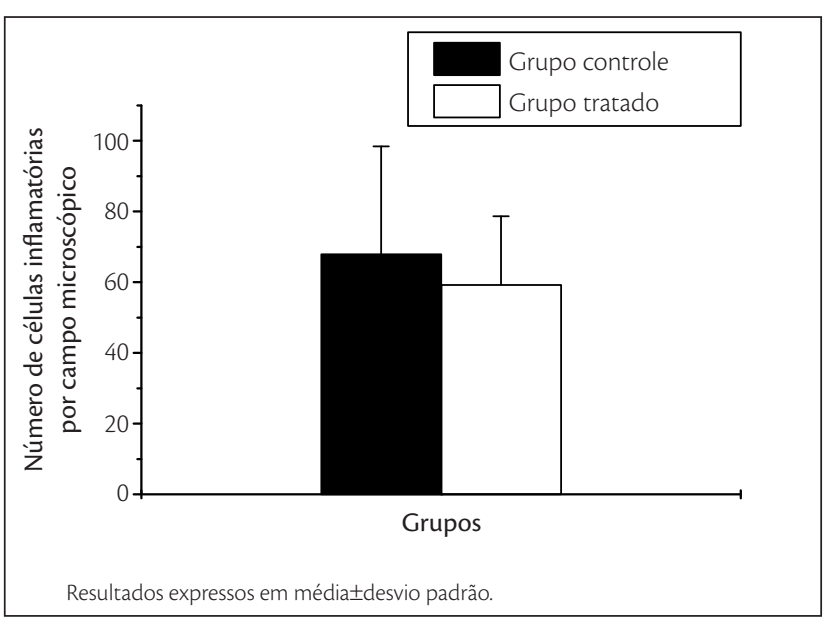

Gráfico 1. Número de células inflamatórias no sétimo dia pós-operatório.

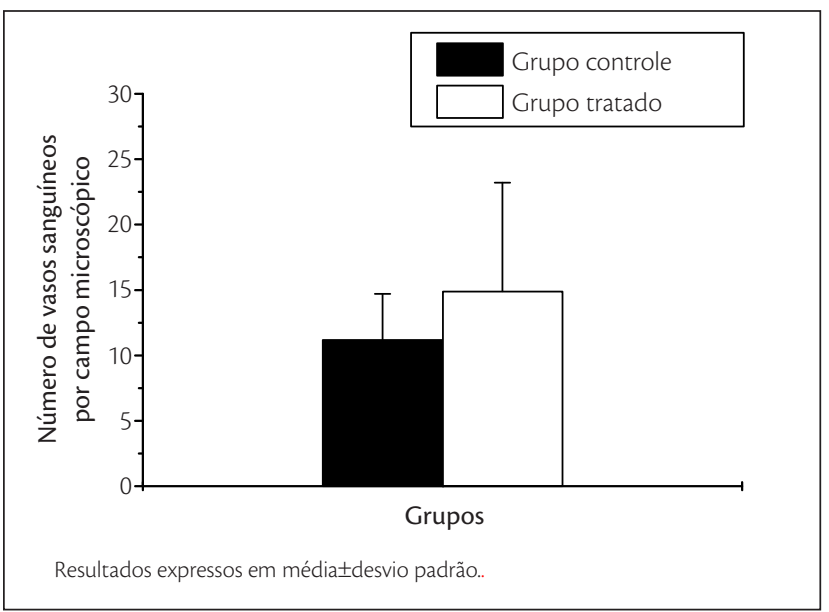

Gráfico 2. Número de vasos sanguíneos no sétimo. dia pós-operatório.

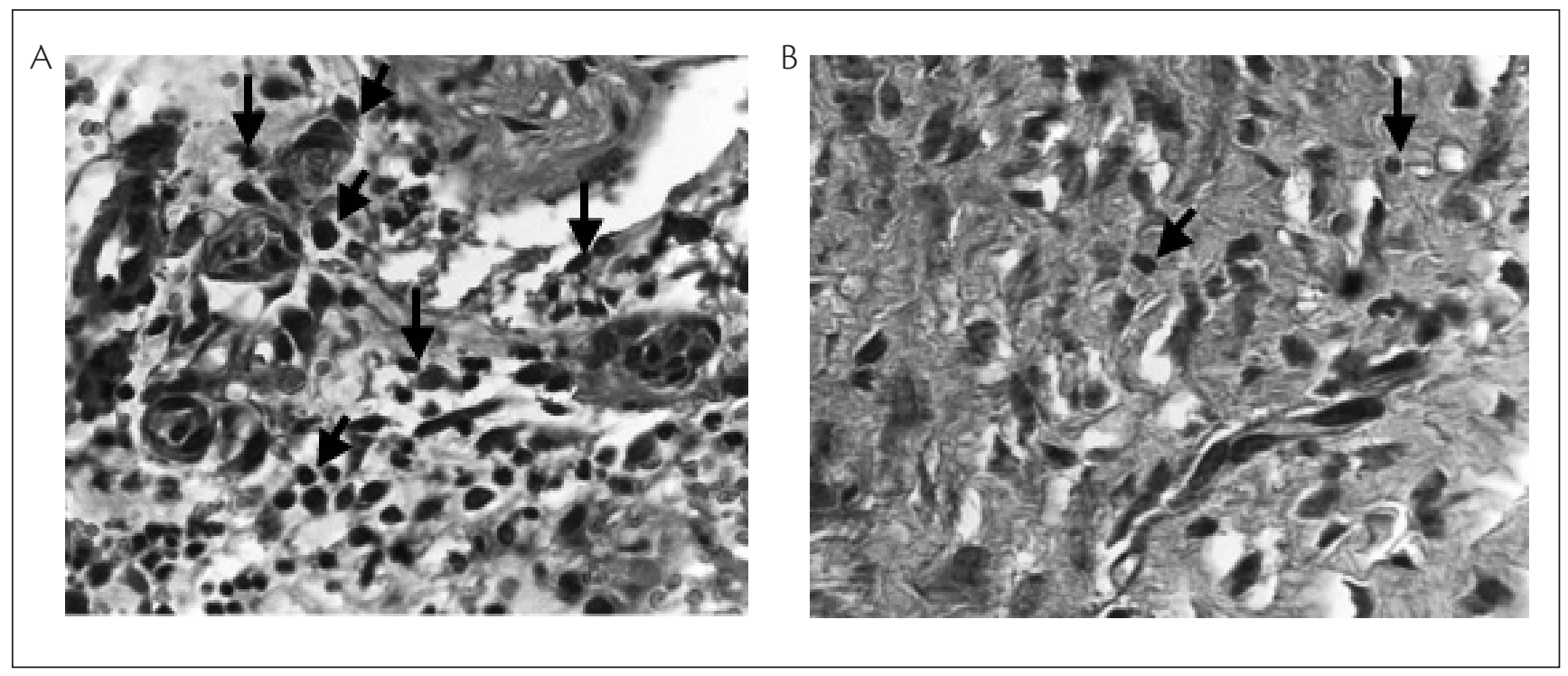

Figura 1. Corte histológico de amostra cutânea de camundongos non obese diabetic. (A) Grupo controle apresentando infiltrado inflamatório mononuclear difusamente distribuído (setas), coloração por hematoxilina e eosina, aumento original 400X. (B) Grupo tratado apresentando escasso infiltrado inflamatório mononuclear (setas), coloração por hematoxilina e eosina, aumento original 200X. 
saudáveis. Isto explica o fato dos diabéticos serem mais susceptíveis a morbidades inerentes a doença o que dificulta o processo cicatricial, como o risco aumentado para infecções, evolução da ferida, podendo levar a amputação do membro afetado ${ }^{18-22}$.

Diante tal realidade, esclarecimentos sobre a doença, modelos animais portadores de diabetes vêm sendo utilizados em pesquisas na busca de respostas sobre as complicações inerentes à doença e meios de evitá-la ${ }^{12,13}$. Estas pesquisas envolvem, classicamente, dois modelos experimentais em animais com DM1 espontânea: ratos biobreading (BB) e camundongos non obese diabetic (NOD). Estes modelos são suficientemente bem caracterizados para se traçar um paralelo com estudos clínicos em humanos ${ }^{12,13}$.

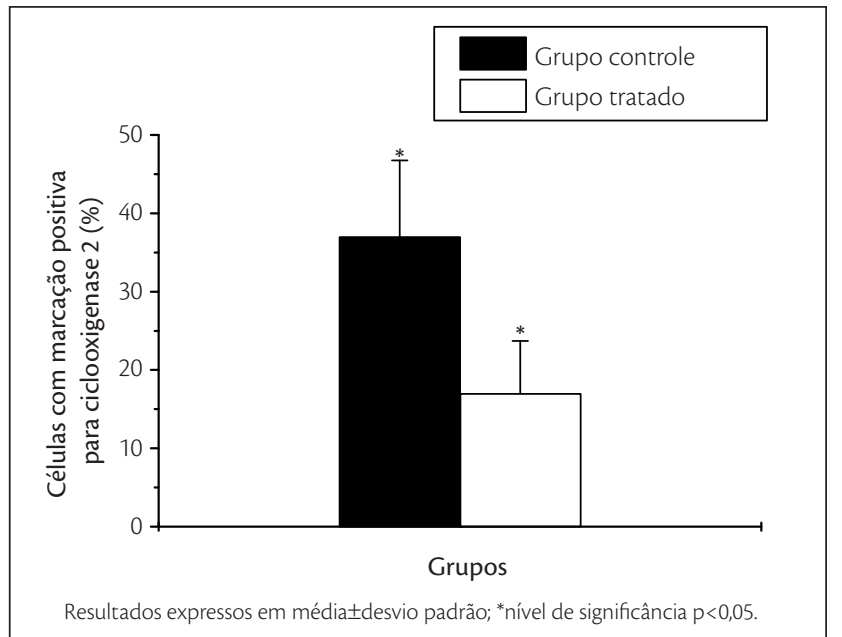

Gráfico 3. Porcentagem de células com marcação positiva para ciclooxigenase 2 no infiltrado inflamatório.
Fisiologicamente, o processo de cicatrização de feridas passa por uma sequência de eventos que envolvem: hemostasia, inflamação (limpeza), proliferação, amadurecimento ou remodelamento e desconstrução ou digestão $\mathrm{O}^{23-25}$. Quando ocorre uma lesão tecidual, o processo de reparo é modulado pela atividade celular das células da resposta inflamatória e das células da borda da lesão e por uma rede de citocinas e de fatores de crescimento que influenciam a migração, a proliferação e a diferenciação celular para o local da lesão tecidual ${ }^{26,27}$.

O TGF- $\beta 2$ é uma citocina pró-inflamatória envolvida em processos fisiológicos e patológicos, incluindo remodelamento vascular (angiogênese e neogênese) e fibrose cutânea ${ }^{26,28-30}$. Ainda, este mediador regula múltiplas funções celulares, incluindo a atividade mitótica e a indução à diferenciação celular ${ }^{31,32}$. Através deste controle, também influencia o aumento da população de fibroblastos que depositam a matriz extracelular (MEC) via síntese de colágeno e inibe a ativação de proteases que degradam esta matriz ${ }^{33}$. Estudo realizado em nosso laboratório, utilizando a LLLT como tratamento de feridas cutâneas em modelo experimental em ratos Wistar, demonstrou níveis elevados de TGF- $\beta$ no grupo tratado em comparação com o grupo controle. Os resultados sugeriram que a LLLT é um método útil e não invasivo para regular a intensidade da reação inflamatória, sendo instrumento importante na cicatrização de feridas cutâneas ${ }^{6}$.

Estudo envolvendo tratamento com LLLT na isquemia cerebral induzida experimentalmente sugere que este tipo de terapia pode inibir a produção do NO e regular a expressão da citocina TGF- $\beta 2$ que apresenta potencial anti-inflamatório além de induzir a proliferação fibroblástica,

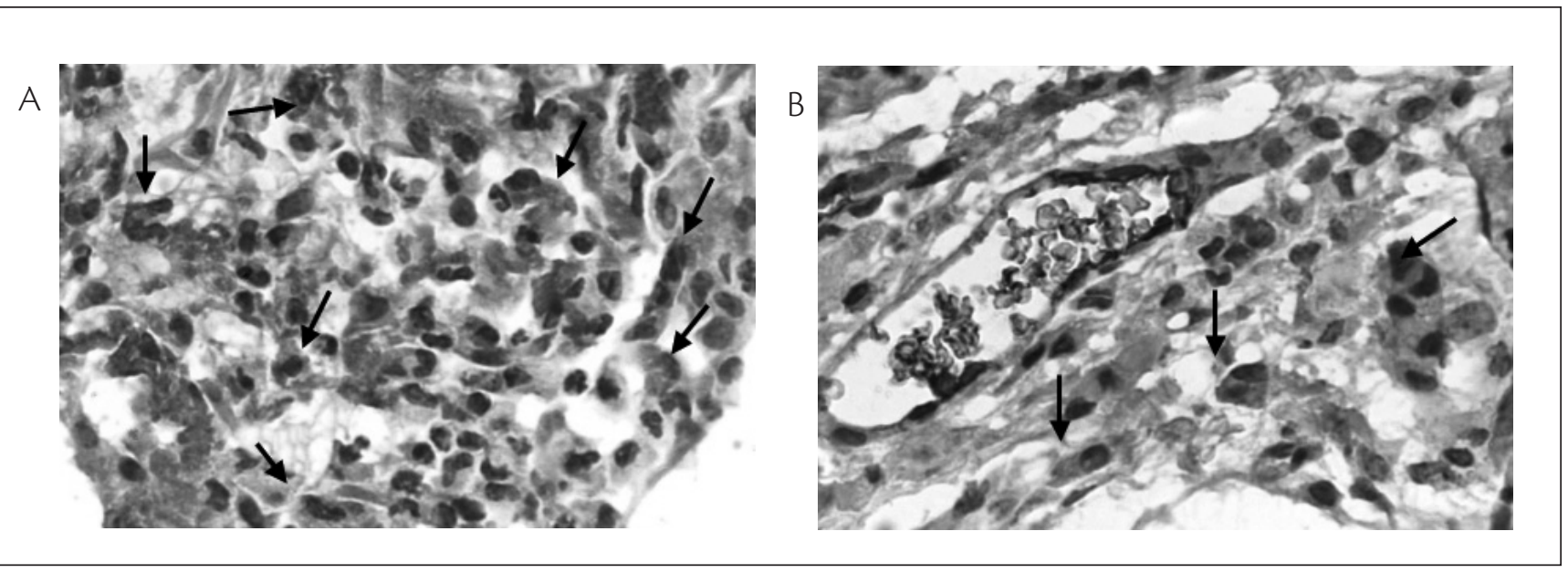

Figura 2. Corte histológico de amostra cutânea de camundongos non obese diabetic. (A) Grupo controle apresentando inúmeras células com marcação positiva para COX2 (setas), coloração por imuno-histoquímica, aumento original 400X. (B) Grupo tratado apresentando pequeno número de células com marcação positiva para COX2 (setas), coloração por imuno-histoquímica, aumento original 400X. 
controlando o processo cicatricial ${ }^{27}$. Diversos pesquisadores também têm estudado o papel imunomodulador pró-inflamatório do $\mathrm{NO}$ através da elevação dos níveis de $\mathrm{COX} 2^{14-17}$. A COX2 pertence à família de enzimas que convertem o ácido araquidônico em prostaglandina (PG). A forma induzível desta enzima é estimulada por citocinas inflamatórias, lipopolissacarídeos (LPS) e fatores de crescimento (FC) ${ }^{34,35}$.

O presente estudo evidenciou maior quantidade de vasos sanguíneos nas lesões no grupo tratado quando comparado ao grupo controle. Em relação às células inflamatórias, observou-se maior quantidade de infiltrado inflamatório no grupo controle quando comparado ao grupo tratado, além do grupo submetido à LLLT apresentar uma cicatrização mais bem organizada. Entretanto, a análise histomorfométrica revelou que a redução da intensidade do infiltrado inflamatório e a indução do processo de reparação tecidual não foram estatisticamente significativas quando comparadas aos dados obtidos das amostras cutâneas dos animais do grupo controle. Estes dados são diferentes dos estudos anteriores ${ }^{6,8,36}$ que demonstram significância estatística no potencial anti-inflamatório e pró-cicatricial da LLLT em animais convencionais ${ }^{8,37,38}$.

Estes estudos acima mencionados reportam a hipótese de que o desenvolvimento do diabetes interfere substancialmente com a resposta inflamatória e cicatricial. Em ratos Wistar não diabéticos foi constatado que a LLLT induz a síntese de TGF- $\beta^{6}$. É possível que citocinas importantes como TGF- $\beta$ que controlam o desenvolvimento do processo inflamatório, a proliferação fibroblástica e a formação de novos vasos sanguíneos apresentem uma expressão tecidual alterada em camundongos diabéticos.

No presente estudo utilizou-se o método imuno-histoquímico para avaliar a expressão da enzima $\mathrm{COX} 2$ pelas células inflamatórias nas feridas cutâneas em camundongos NOD. Foi constatada uma redução significativa da expressão de COX2 em animais tratados com a LLLT. Esta diminuição foi associada à redução do infiltrado inflamatório e ao aumento de número de vasos sanguíneos nos animais tratados com LLLT.

\section{Conclusão}

Em conjunto, os resultados sugerem que a LLLT é capaz de modular negativamente a expressão da enzima COX2 contribuindo para o controle da resposta inflamatória em feridas cutâneas de camundongos NOD.

\section{Referências}

1. Carvalho CBM, Motta Neto, Aragão LP, Oliveira MM, Nogueira MB, Forti AC. Pé diabético: análise bacteriológica de 141 casos.
Arq Bras Endocrinol Metabol. 2004;48(3):398-405. http://dx.doi. org/10.1590/S0004-27302004000300012

2. Milech A, Oliveira JEP. Diabetes mellitus: clínica, diagnóstico, tratamento multidisciplinar. São Paulo: Atheneu; 2004.

3. American Diabetes Association. Economic consequences of diabetes mellitus in the U.S in 1997. Diabetes Care. 1998;21(2):296-309. PMid:9539999.

4. Margolis DJ, Berlin JA, Strom BL. Risk factors associated with the failure of a venous leg ulcer to heal. Arch Dermatol. 1999;135(8):9206. PMid: 10456340.

5. Fernandes ARC, Peçanha PC, Turrini E, Natour J. Avaliação por imagem do pé diabético. Rev Bras Reumatol. 2001;41(5):305-8.

6. Rocha Júnior AM, Vieira BJ, Andrade LC, Aarestrup FM. Low-level laser therapy increases transforming growth factor- $\beta 2$ expression and induces apoptosis of epithelial cells during the tissue repair process. Photomed Laser Surg. 2009; 27 (2): 303-7. http://dx.doi. org/10.1089/pho.2008.2277

7. Viegas VNO, Abreu ME, Viezzer C, et al. Effect of low-level laser therapy on inflammatory reactions during wound healing: comparision with meloxicam. Photomed Laser Surg. 2007;25(6):467-73. PMid:18158747. http://dx.doi.org/10.1089/pho.2007.1098

8. Rocha Júnior AM, Oliveira RG, Farias RE, Andrade LCF, Aarestrup FM. Modulation of fibroblast proliferation and inflammatory response by low-intensity laser therapy in tissue repair process. An Bras Dermatol. 2006;81(2):150-6. http://dx.doi.org/10.1590/ S0365-05962006000200006

9. Weis LC, Arieta A, Souza J, Guirro R. Utilização do laser de baixa potência nas clínicas de fisioterapia de Piracicaba, SP. Fisioter Bras. 2005;6(2):124-9.

10. Buschard K, Hanspers K, Fredman P, Reich EP. Treatment with sulfatide or its precursor, galactosylceramide, prevents diabetes in NOD mice. Autoimmunity. 2001;34(1):9-17. PMid:11681495.

11. Leiter $E H$, von Herrath $M$. Animal models have little to teach us about type 1 diabetes: 2 . In opposition to this proposal. Diabetologia. 2004;47:1657-60. http://dx.doi.org/10.1007/ s00125-004-1518-0

12. Homo-Delarche F. Is pancreas development abnormal in the non-obese diabetic mouse, a spontaneous model of type I diabetes? Braz I Med Biol Res. 2001;34:437-47. http://dx.doi.org/10.1590/ S0100-879X2001000400002

13. Atkinson MA, Leiter EH. The NOD mouse model of type 1 diabetes: as good as it gets? Nat Med. 1999;5(6):601-4. http://dx.doi. org/10.1038/9442

14. Baliga RS, Chaves AA, Jing L, Ayers LW, Bauer JA. AIDS-related vasculopaty: evidence for oxidative and inflammatory pathways murine and human AIDS. Am J Physiol Heart Circ Pysiol. 2005;289(4):H1373-80. PMid:15923317.

15. Suschek CV, Schnorr O, Kolb-Bachofen V. The role of iNOS in chronic inflammatory process in vivo: is it damage-promoting, protective, or active at all? Curr Mol Med. 2004;4(7):763-75. PMid:15579023.

16. Batista AC, Silva TA, Chun JH, Lara VS. Nitric oxide synthesis and severity of human periodontal disease. Oral Dis. 2002;8 (5):254-60. PMid:12363110. 
17. Bezerra MM, Lima $\vee$, Alencar $\vee B$, et al. Selective cyclooxigenase-2 inhibition prevents alveolar bone loss in experimental periodontitis in rats. J Periodontol. 2000;71(6):1009-14. PMid:10914805. http://dx.doi.org/10.1590/S1806-83242005000100007

18. Boulton AJM. The diabetic foot: an update. Foot Ankle Surg 2008;14(3):120-4. PMid:19083628.

19. Wu SC, Jensen JL, Weber AK, Robinson DE, Armstrong DG. Use of pressure offloading devices in diabetic foot ulcers: do we practice what we preach? Diabetes Care. 2008;31(11):2118-9. PMid:18694976.

20. Chen MC, Lee SS, Hsieh YL, Wu SJ, Lai CS, Lin SD. Influencing factors of outcome after lower-limb amputation: a five-year review in a plastic surgical department. Ann Plast Surg; 2008;61(3):314-8. PMid:18724135.

21. Lincoln NOB, Radford KA, Game FL, Jeffcoate WJ. Education for secundary prevention of foot ulcers in people with diabetes: a randomised controlled trial. Diabetologia. 2008;51(11):1954-61. http://dx.doi.org/10.1007/s00125-008-1110-0

22. Gardner SE, Frantz RA. Wound bioburden and infection-related complications in diabetic foot ulcers. Biol Res Nurs. 2008;10(1):44-53. http://dx.doi.org/10.1177/1099800408319056

23. Rocha Júnior AM, Vieira B), Andrade LCF, Aarestrup FM. Effects of the low-level laser therapy on the evolution of the wound healing in human: the contribution of in vitro and in vivo experimental studies. I Vasc Bras. 2007;6(3):258-66.

24. Singer AJ, Clark RA. Cutaneous wound healing. N Engl J Med. 1999;341(10):738-46. PMid:10471461.

25. Thomas DW, O'Neill ID, Harding KG, Shepherd JP. Cutaneous wound healing: a current perspective. J Oral Maxilofac Surg. 1995;53(4):442-7. PMid:7699500.

26. Murphy MO, Ghosh J, Fulford P, et al. Expression of growth factors and growth factor receptor in non-healing and healing ischaemic ulceration. Eur I Vasc Endovasc Surg. 2006; 31(5):516-22. http:// dx.doi.org/10.1016/j.ejvs.2005.12.002

27. Leung MC, Lo SC, Siu FK, So KF. Treatment of experimentally induced transient cerebral ischemia with low energy inhibits nitric oxide synthase activity and un-regulates the expression of transforming growth factor-beta 1. Lasers Surg Med. 2002;31(4):283-8.

28. Wu XY, Yang YM, Guo H, Chang Y. The role of connective tissue growth factor, transforming growth factor beta 1 and Smad signaling pathway in cornea wound healing. Chin Med I (Engl). 2006;119(1):57-62. PMid:17217787.

29. Cipollone F, Fazia M, Mincione G, et al. Increased expression of transforming growth factor- $\beta 1$ as a stabilizing factor in human atherosclerotic plaques. Stroke. 2004;35(10):2253-7. http://dx.doi. org/10.1161/01.STR.0000140739.45472.9c

30. Ihn H. Pathogenesis of fibrosis: role of TGF-beta and CTGF. Curr Opin Rheumatol. 2002;14(6):681-5. PMid:12410091.

31. Maier P, Broszinski A, Heizmann $U$, Boehringer D, Reinhard $T$. Determination of active TGF-beta2 in aqueous humor prior to and following cryopreservation. Mol Vis. 2006;12:1477-82. PMid:17167403.

32. Yasuda K, Aoshiba K, Nagai A. Transforming growth factor-beta promotes fibroblast apoptosis induced by $\mathrm{H}_{2} \mathrm{O}_{2}$. Exp Lung Res. 2003;29(3):123-34. PMid:12637225.

33. Bernasconi $P$, Torchiana E, Confalonieri $P$, et al. Expression of TGF-beta 1 in dystrophic patient muscles correlates with fibrosis. Pathogenetic role of a fibrogenic cytokine. J Clin Invest. 1995;96(2):1137-44.

34. Salvemini D. Regulation of cyclooxigenase enzymes by nitric oxide. Cell Mol Life Sci. 1997;53(7):576-82. PMid:9312403.

35. Lohinai Z, Stachlewitz R, Székely AD, Fehér E, Dézsi L, Szabó C. Evidence for the expression of cyclooxigenase-2 enzyme in periodontitis. Life Sci. 2001;70(3):279-90. PMid:12005261.

36. Rabelo SB, Villaverde AB, Nicolau R, Salgado MC, Melo MS, Pacheco MT. Comparison between wound healing in induced diabetic and nondiabetic rats after low-level laser therapy. Photomed Laser Surg. 2006;24(4):474-9. PMid:16942427.

37. Byrnes KR, Barna L, Chenault VM, et al. Photobiomodulation improves cutaneous wound healing in an animal model of type II diabetes. Photomed Laser Surg. 2004; 22(4):281-90. PMid:15345169. tp://dx.doi.org/10.1089/pho.2004.22.281

38. Demir $\mathrm{H}$, Balay $\mathrm{H}$, Kirnap MA. A comparative study of the effects of electrical stimulation and laser treatment on experimental wound healing in rats. J Rehabil Res Dev. 2004;41(2):147-54.

Correspondência
Prof. Fernando Monteiro Aarestrup
Rua Dr. Jamil Altaf, 235 - Vale do Ipê
CEP 36035-380 - Juiz de Fora (MG), Brasil
E-mail: fmaarestrup@hotmail.com
Contribuições dos autores
Análise e interpretação dos dados: CLJVR, FMA, BJVA, AMRJ
Coleta de dados: CLJVR, FMA
Redação do artigo: CLJVR, FMA
Revisão crítica do texto: AMRJ, BJVA
*Todos os autores leram e aprovaram a versão final submetida ao J Vasc Bras.
Análise estatística: CLJVR, AMRJ, FMA

